\title{
Computer systems in terms of fulfilling local and global challenges
}

\author{
Dr Irshad Ullah
}

Education Department, Government of KPK, Islamabad, Pakistan

Email address

irshadullah79@gmail.com

\section{To cite this article:}

Irshad Ullah. Computer Systems in Terms of Fulfilling Local and Global Challenges. International Journal of Science, Technology and Society. Special Issue: Global Warming Effects, Recovery, Management in the Rapid Changing Phenomena. Vol. 3, No. 1-3, 2015 , pp. 1-3.

doi: 10.11648/j.ijsts.s.2015030103.11

\begin{abstract}
Computer is a programmable machine. This means that it can perform a programmed list of instructions and respond to new directions those are given. A computer is a device that receives input, stores and manipulates data and provides output in a useful format. In this research work, we have to study role of computer in managing and helping human in every part of life. Computer helps and control human movements in every field. Computer is a modern wonder of the world. In this study it will be discussed that how much computer is helpful in our daily life and how it is possible to make improvements for more accurate, efficient and fast performance. It will also be proved that's from where computer start who is the initiator of the computer and how it became modern wonder of the world. In present times, we see that computer systems play a significant role everywhere from theoretical to practical and because of this that it connect the whole world with its interconnectivity facility and the world has become a global village.
\end{abstract}

Keywords: Computer, Challenges, Initiator, Global Challenges

\section{Introduction}

Computer is derived from compute means Calculation. Computer is a machine work on programs to receive the input, make the processing and give the data in the form of output. First computer was developed in 1940-1945. The size of the computers developed initially very large. These computer developed in the early age were very power consuming (Computer. 2010). Today's computers are very powerful compare to the initial stages while these are very smaller in size as compare to the early stage of machines (Wikipedia, The Free Encyclopedia. 2015).

For the first time the word computer was used in 1613, means a person who makes the calculation. This sense was used until the mid of the $20^{\text {th }}$ century. From $19^{\text {th }}$ century the word is used for a computer to make the calculation (Oxford English Dictionary. 1989) (Wiet,G. Elisseeff,V. Wolff,P. Naudu,J. 1975).

In short, it is saying that computer is anything to give meaningful information. May be it does not contain the hardware like hard disk, Ram or even a processor (Charette, F. 2006). (Silvio, A.; Bedini, F. R. and Maddison. 1966). (Price, D. S. 1984).

\subsection{Computer Components}

\subsubsection{Hardware}

The physical portion of the computer that can be touch is hardware. This portion may contain processor, Ram, Mother Board and other input and output devices.

\subsubsection{Software}

This portion may contain the programs to carry out some task. Software may be of the type system software and application software broadly.

\section{Role of Computer Systems in Different Areas}

\subsection{Computer in Education}

Computer plays very important role in the field of education. It is used for different purposes like to make the software for any component to make it computerize. After the computerization the work become very consistent and also it increase the speed of the system. In educational institution specially the official work become speedier and fast by the use of this device. With the help 
of Computer students may record their lectures for future use. In some circumstances its act likes a teacher for the students.

\subsection{Computer in Medical}

In the field of medical computer play a significant role. Databases may be developed to make the work accurate and speedy. Doctors may use it for the secure storage of the patient data. The patient data may be simultaneously access from anywhere by different personnel and can be easily edited. Printed charts are more accurate and reliable and easy to see in comparison to that of handwritten charts. Medical data which is required for future use can easily be stored by backup procedures and may be available in future if required.

Also the data can be stored by giving passwords from unauthorized access. Data can be displayed in different format. Different screen displays can be used. Data stored in computers can be available to all doctors by keeping in a central location and connecting different side by network. Data can be accessed by different doctors regardless of their location. Hard copy of the data can be obtained by the output devices in different colors and fonts.

\subsection{Computer in Engineering}

In the field of engineering use of computer is very vast. Engineering is now possessing different branches of computers like system engineering and software engineering. These are very broad and wide branches of computer in the field of engineering. It's make the work of engineers reliable and consistent. Different engineering tools are used like $\mathrm{CAE}$ and $\mathrm{CAD}$.

\subsection{Computer in Business}

As business is a very vast field. A lot of peoples are working and earning from this field. This field provides jobs to a lot of peoples. It is a very versatile field. Computer adds a new dimension to this field by integrating its work. Now computer is used by the business peoples for different purposes like software's are used to speed up and secure its work. Internet is used here to speed up the communication process. Gigabyte and even tera byte of the data can be stored.

\subsection{Computer in Defense}

As defense is a very sensitive field. By the entry of computer systems the way of operation of the troops either working in the air or in the sea or on ground has changed. In fast while fighting with each other they will not aware of their targets and they drop bombs on the area which result a large amount of casualties and destruction.

As there are examples of World War I and World War II how much destruction they did. They destroy even the countries and also a huge amount of loss in human. Now with the help of computers these destructions are minimized. It's easy to reduce the loss in terms of humans and property destruction because computer can help to identify the targets. Also they can use computers in dangerous areas instead of humans. The data of the military are also secure.

As wars are predictable so to reduce the destruction weapons must be made so intelligent to hit the specific target and live the remaining property undestroyed. As with the help of projectile motion a target may be targeted specifically. This strategy is less expensive in the long run by using the resources more efficiently.

If it is necessary in a war to hit humans so here a strategy must be present to decide a particular target and leave the peoples who are not involved in the war. To do this lasers and computer are used to process it. US military systems used broadly the global positioning systems for the required purpose. It is not possible to launch a projectile without the help of machine systems. Computer is also very necessary in this process. Also computer can take the pictures and then send it to other computer for analysis. Here the intelligence personnel have to take the decision on the basis of the data obtained. United State uses KH-1 for that purpose with the help of which they are able to know about their targets.

\subsection{Computer in Space Science}

Computer systems are very helpful in space sciences. It gives a new way to the field of space sciences. Rad-hard chips are used by the scientist for more accurate work. NASA relies on these chips. The scientist uses the CPU's on moon or mars surface to collect and analyze the data.

\section{7. e-Government}

e-government uses computer to improve the work of public organizations. In e-government e-administration is the portion to regularize the work of the administration portion of the sector. Also it connects the citizen to each other by e-citizen. Also it reduces the cost of the organizations by applying different techniques.

Developing Strategic Combination in Government: In this process government agencies are making strengthen by collecting the data to facilitate investigation

Conversation with the Citizen: In this process the detail service activities have to provide to the people. This may have to make the citizen more accountable and workable regarding their activities like decision making.

Responding to the People: here the people are involved in the decision of the public sector this may be refer involvement or democratization

Working Better with the Business: This may refer to the relation of the business community with the government. Here the interaction is made in such a way is to improve the performance

Making Communities: Communities have to do work to make productive community. Here in this, people are socially involved to work with each other to solve different problems with different methods and then the data is to be stored for future use.

\subsection{Computer in Environmental Science}

Environmental Science is also very important and computer can be used. People are using in today global world the term "Green Computing" peoples are unaware that what this term means. It is the use of computer sciences resources for the betterment of the environment and to save the energy. The main 
target of the green computing is to give help to triple bottom line. That is used for the success of organization which is also similar to green chemistry. Green computing actually help to recycle machine equipments.

For the first time green computing is used in 1992 when EPA make energy stars. That is to facilitate and promote energy efficient calculation. For the first time in history it is because of this creation that computer manufacturer introduces sleep mode in their systems for the saving of energy while not using the computers. The green computing terminology is begun to be used by the peoples at that time. Many government agencies start to help and struggle for better standards for campiness for the promotion of green computing. Energy star was revised once again in 2006 to make more strict ranking systems for the creation of products.

\section{Green IT Systems}

Now a day most of the IT systems depend on both people and as well as on hardware for the purpose to take the computer systems to the green computing more nearly. This well helps the company and also more. But to achieve this is not easy because it requires the satisfaction of all like users, campiness and also the management. This is for the purpose to keep everyone in the circle happy.

Green computing is the new term, so mostly the home users are not familiar with this. This is started and become the mainstream and necessary for both the user and the manufacturers and also for the environment.

\section{Computer in Industry}

The use of computer in business is very wide now a days. This is more use full for the utilization of their resources more accurately and efficiently. This is because of this that IT jobs were advertised by the campiness in a huge amount.

\subsection{Inventory Control}

The benefit of inventory control systems is to maximize company or organization's production by using less inventory investment. That is to check the store of the business.

\subsection{Payroll}

Most of the industries are largely depend on computer payroll systems.

\subsection{Cash Registers}

Computers in a networking environment are just like cash registers for the record keeping purpose more accurately

\subsection{Websites}

Now a day, business communities are using web sites for its work. Like advertising, Online shopping, Customers record storage. Simply these websites make the industry work more efficient and consistent. Websites may be used to keep the customers aware of everything. It gives a new dimension to the world of industry.

\subsection{Customer Databases}

Customer databases are used for the storage of data. It helps in tracking as well as good performance for the future. The customer databases are used for the analysis purpose to analyze the trend.

\section{Conclusion}

In this paper an attempt has been made to identify use and application of computer in different field of life as well as in the whole universe. So here we see that computer facilitate and control the life. And also the whole world is connected together with the help of international network and also the universe by sending messages from the space and different planets to the human world. Some fields are discussed to show that really computer systems play a vital role in these systems and organizations. It is shown that the efficiency after and before are very different. This add a new edge to these systems

\section{Future Work}

In future it is possible to extend the work in different direction for different fields. It is also possible to study each field separately and make the analysis to increase its performance, efficiency and working capacity of the organizations.

\section{References}

[1] Computer. (2010). Penn Information Systems and Computing. Retrieved from https://secure.www.upenn.edu/computing/resources/category/hard ware/article/computer-power-usage

[2] Oxford English Dictionary. (1989). (2 Ed.). Oxford University Press. Retrieved from http://dictionary.oed.com/.

[3] Wikipedia, The Free Encyclopedia. (2015). Computer Origin. Retrieved from http://en.wikipedia.org/wiki/Computer\#cite_note-1

[4] Wikipedia, The Free Encyclopedia. (2015). Computer. Retrieved from https://en.wikipedia.org/wiki/Computer

[5] Wiet,G. Elisseeff,V. Wolff,P. Naudu,J. (1975). History of Mankind

[6] Sezgin, F. (2004). Catalogue of the Exhibition of the Institute for the History of Arabic-Islamic Science (at the Johann Wolfgang Goethe University, Germany)

[7] Charette, F. (2006). Archaeology: tall tech on or after early Greece

[8] Silvio, A.; Bedini, F. R. and Maddison. (1966). Mechanical Universe: The Astrarium of Giovanni de' Dondi.

[9] Price, D. S. (1984). A History of Calculating Machines, IEEE Micro

[10] Oren, T. (2001). Advances in Computer and Information Sciences: From Abacus to Holonic Agents, Turk J Elec Engin, 9 (1), p. 63-70

[11] 11 Hill, D.R. (1985). Al-Biruni's mechanical calendar", records of Science 